\title{
Analysis of the Evolution of Hazardous Chemical Waste from Medicolegal Activities
}

\author{
ANA FULGA ${ }^{1}$, DAN PERJU-DUMBRAVA ${ }^{2}$, ANAMARIA CIUBARA ${ }^{\mathbf{1}}$, \\ CARMINA LIANA MUSAT ${ }^{1 *}$, CLAUDIU MEREUTA ${ }^{1 *}$, \\ ANDRA IRINA BULGARU-ILIESCU ${ }^{3 *}$, BOGDAN ALEXANDRU CIUBARA ${ }^{\mathbf{1}}$ \\ ${ }^{1}$ Dunarea de Jos University of Galati, 47 Domneasca Str., 800008, Galati, Romaneasca \\ ${ }^{2}$ University of Medicine and Pharmacy "Iuliu Hatieganu" 8 Victor Babes Str., 400012, Cluj, Romania \\ ${ }^{3}$ University of Medicine and Pharmacy "Grigore T. Popa” 16 Universitatii Str., 700115, Iasi, România
}

\begin{abstract}
The paper presents an analysis of the management of hazardous chemical waste from medicolegal. activities. The analysis is based on eight years survey of the hazardous chemical waste management, ponting out the current procedures. The time series analysis is used to predict the evolution of such medical waste, and according to the forecast some strategic objective for reducing the amount of chemical waste are proposed.
\end{abstract}

Keywords:chemical waste, medicolegal, waste management

\section{Introduction}

The management of medical waste is the regulation of how medical waste is collected, packaged, stored, transported and disposed of, with particular attention to hazardous waste, in order to prevent environmental contamination and harming the population's health [1,2].

Medicolegal activities include performing a forensic expertise on living victims of assault, on corpses, on documents and in the laboratory (toxicology, histopathology, genetics, serology) [3-11], resulting in a wide rage of waste.

Chemical and pharmaceutical wastes are solid, liquid or gaseous chemical substances that can be toxic, corrosive or flammable, expired drugs and residues of chemotherapeutic substances, etc.Collection and separation of waste categories is the first stage in the management of hazardous waste resulting from medical activity.Collection from temporary storage areas is carried out regularly and takes into account the rate of waste generation, the available storage capacity, and the control of odors emanating from waste.Hazardous chemical wastes from health units are collected in special containers, with appropriate markings and treated according to the legal provisions. Are collected and packed in containers of not more than 5 liters for liquid substances and not more than $5 \mathrm{~kg}$ for solids. Hazardous chemical wastes from sanitary units are collected separately and disposed of by incineration, after their thermal reactivity has been tested $[12,13]$.

\section{Materials and methods}

This study uses as a basis the analysis of hazardous chemical waste obtained in the forensic medicine section of a county hospital for the last 8 years. Procedures for the management of chemical medical waste are also presented.

The methods of analysis are statistical and are based both on the analysis of the evolution over time of the different categories of waste and on the forecasting of their development over time on the basis of time series.

The moving average method is the statistical tool used for data analysis and obtaining predictions for the next 5 years.

The chronological series used were obtained by systematizing the consumption of substances registered for 8 years. Thus, seasonal component, irregular component and trend component were calculated, and by combining them the prediction for the next 5 years was determined.

*email: carmina.musat@ugal.com claudiu.mereuta@ugal.roandra_irina_ai@yahoo.com 
Table 1 shows the status of chemical waste resulting from the activity of the forensic medical section, namely histopathology for the last 8 years. The chemical substances that are considered hazardous waste and are collected and treated as such are: benzene, xylene, paraffin, ethyl alcohol, hematoxylin, eosin, carboxylol, lithium carbonate.

Table 1.Chemical waste from forensic medical activities - histopathology.

\begin{tabular}{cccccccccc}
\hline Year & 2012 & 2013 & 2014 & 2015 & 2016 & 2017 & 2018 & 2019 & Average \\
\hline Benzene [1] & 15 & 18 & 14 & 29 & 22 & 18 & 19 & 23 & 19.75 \\
\hline Xylene [1] & 16 & 26 & 12 & 21 & 16 & 51.5 & 39 & 31 & 26.56 \\
\hline Paraffin [kg] & 9 & 19 & 30 & 46 & 48 & 175 & 140 & 215 & 85.25 \\
\hline Ethyl alcohol [1] & 135 & 130 & 125 & 165 & 155 & 168 & 130 & 170 & 147.25 \\
\hline Hematoxylin [1] & 2 & 2 & 2.5 & 3 & 3 & 4.5 & 3 & 5 & 3.125 \\
\hline Eosin [1] & 2 & 2 & 2.5 & 3 & 3 & 4.5 & 3 & 4 & 3 \\
\hline Carboxylol [1] & 2 & 2 & 2.5 & 3.5 & 3.5 & 4.5 & 1 & 1 & 2.5 \\
\hline Lithium carbonate [1] & 3 & 3 & 5 & 3 & 3 & 4.5 & 5 & 5 & 3.93 \\
\hline
\end{tabular}

In addition, toluene, dilute acid mixtures and mixtures of organic solvents are obtained from the activity of the forensic medical section, namely the toxicology activity. Dilute acid mixtures contain dilute nitric acid, dilute sulfuric acid, potassium iodide, potassium bicarbonate, sodium thiosulphate.The organic solvent mixtures contain acetonitrile, methanol and methylene chloride.

The paper also shows the trend of this chemical waste, based on the data collected over the last four years (Table 2) and the simple regression as a statistical method.

Table 2.Chemical waste from forensic medical activities - toxicology.

\begin{tabular}{cccccc}
\hline Year & 2016 & 2017 & 2018 & 2019 & Average \\
\hline Toluene [1] & 15 & 73 & 56 & 61 & 51.25 \\
\hline Dilute acid mixtures[1] & 20 & 40 & 20 & 20 & 25 \\
\hline Organic solvent mixtures [1] & 18 & 30 & 20 & 20 & 22 \\
\hline
\end{tabular}

According to current procedures and practices, the collection and separation of medical waste is carried out at the place of its production, according to the categories set out in current legislation.

The responsibility for waste management is of the manager, who initiates, implements and manages the medical waste management system, approves the plan for the management of medical waste based on internal regulations.

Separating in site the non-hazardous waste from the hazardous waste, determines the decreasing of the quantity of hazardous waste. Both the quantities and the types of waste resulting from the medical activity vary according to several factors, such as: the size of the medical unit, the specific of the medical activity, etc.

Each medical unit has the obligation to know the types of waste, the quantities it produces, the management mode, the transportation mode and the final disposal.

The cycle production, collection, transport, final disposal is kept under control by recording the data, by monthly and annually monitoring the medical waste. The methods used to eliminate waste must not endanger the health of the population and the environment.

In accordance with the provisions of the law, the collection of waste is done in a controlled way in special containers and properly labeled. These are delivered periodically to the company specialized in waste destruction. Delivery to the specialized company is done every three months or less, if needed. Within the forensic laboratory, an employee is designated to be responsible for labeling, weighing and delivering the chemical waste to the authorized company. Waste is collected separately by category, as follows: 
- $\quad$ solvents are collected separately, the chlorinated organic and the non-chlorinated solvents;

- base or acid solutions, are collected after a preliminary dilution;

- $\quad$ reagent solutions prepared in the laboratory with expiry date;

- expired reagents.

The collection of solvents and solutions is done separately in plastic containers, properly labeled. Expired reagents are delivered in the original packaging. Security measures require that the personnel involved in the application of this procedure will strictly comply with the labor protection norms regarding working with dangerous substances.

\section{Results and discussions}

The analysis of the data recorded in the medicolegal unit of the county hospital reveals that in 2015 the amount of chemical waste increased for all substances, except for thelithium carbonate. The highest increase is recorded at benzene, 107,1 \% compared with 2014.In 2018 all chemical waste decreased, the most important decreasing was registered for carboxylol $(77.78 \%)$, exception for benzene that increases by $5.6 \%$.

The systematization of the data according to time leads to chronological, dynamic or time series. By studying the time series, the main objective is to obtain information regarding the variation in time, the influence of the factors that caused the deviation from the normal evolution, the factors that have manifested in the evolution of phenomena and processes.For example, for the quantity of benzene as a chemical waste, the seasonal irregularity in 2015 was $30 \%$ above the reference level (CMA), while in 2017 it was 9\% below the base level (Figure 1), where CMA is the center moving average and forecast is the seasonal prediction resulting from combining the components and the irregular trend.

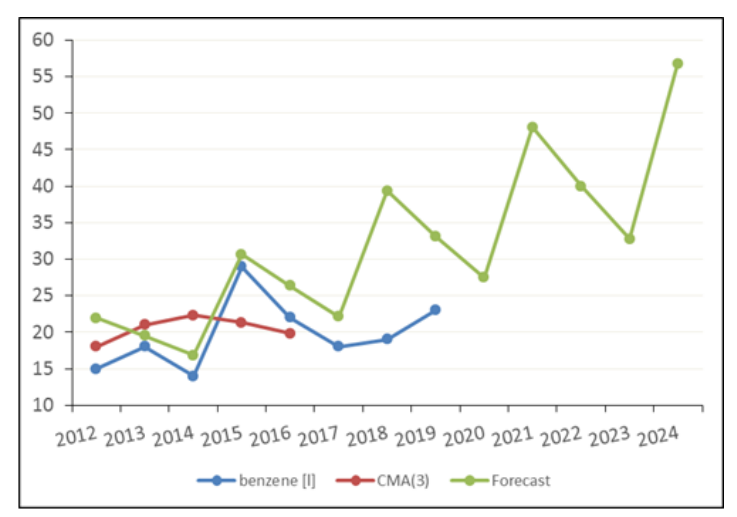

Figure 1. Forecast of benzene chemical waste

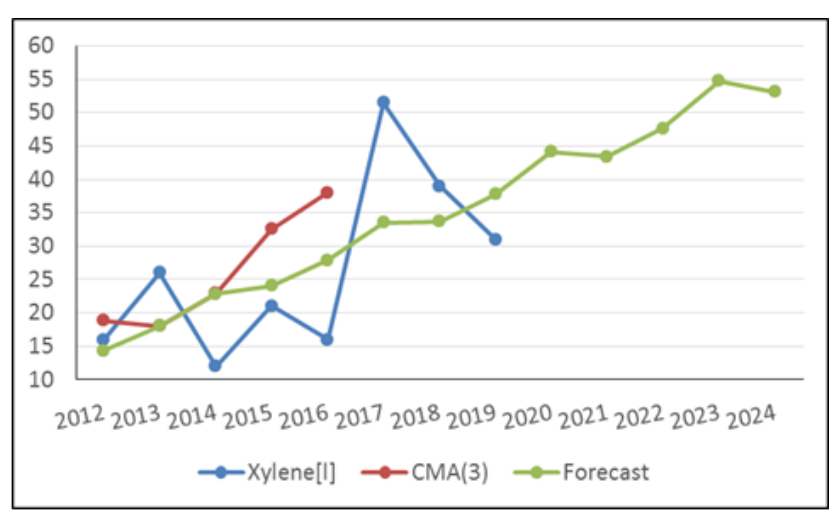

Figure 2. Forecast of Xylene chemical waste

Regarding the quantity of xylene as hazardous chemical waste, the results revealed that the irregularities of the season were 38\% above the base line in 2013 and 51\% below in 2016 (Figure 2).

From the point of view of the seasonal component, the amount of ethyl alcohol (actually and predicted) as chemical waste for all the years analyzed was $2-5 \%$ below the baseline level (Figure 3 ), while the quantity of eosin as a hazardous chemical waste in 2014 was $8 \%$ above the reference level and $14 \%$ below the reference level in 2019 (Figure 4). 


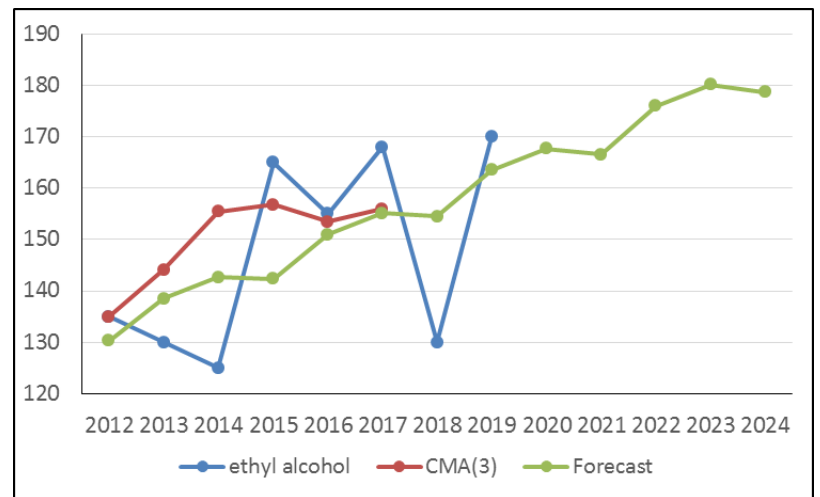

Figure 3. Forecast of ethyl alcohol waste

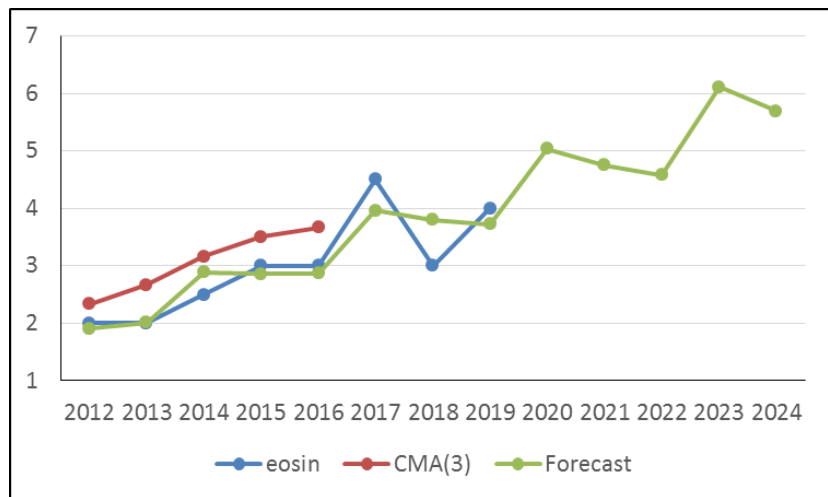

Figure 4. Forecast of eosin chemical waste

Similar interpretations can be made for the other quantities of chemicals considered hazardous waste (figures 5-8).

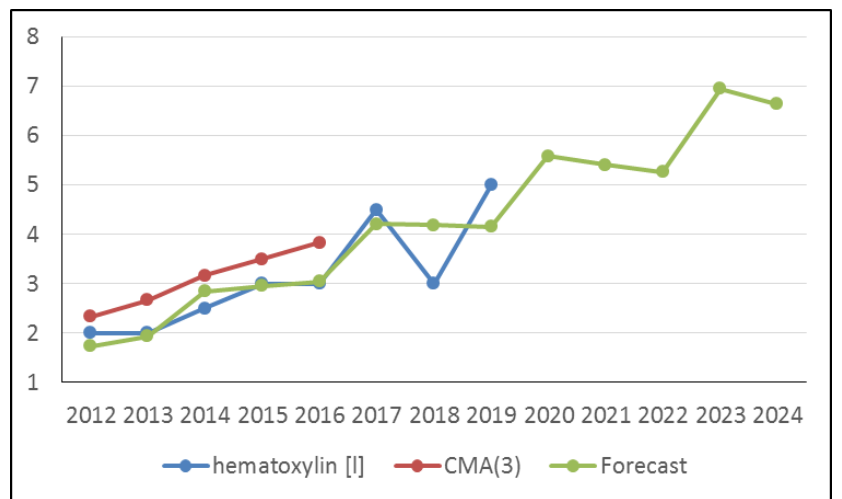

Figure 5. Forecast of hematoxylin waste

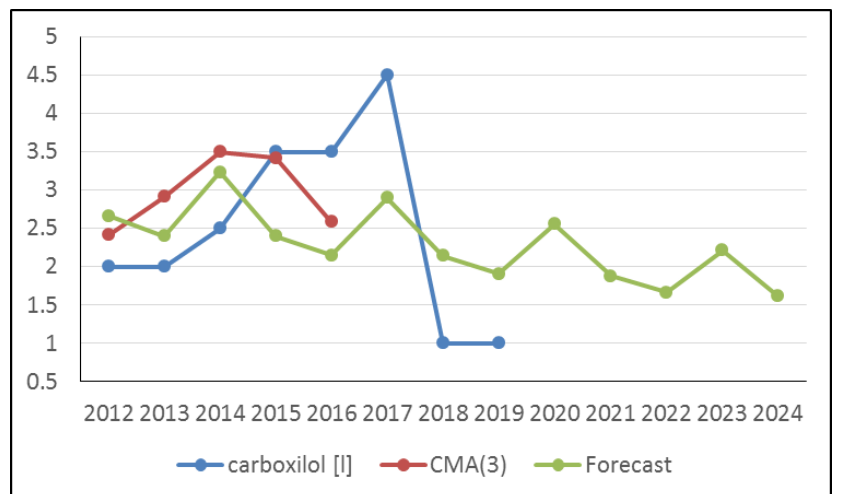

Figure 7. Forecast of carboxilolwaste

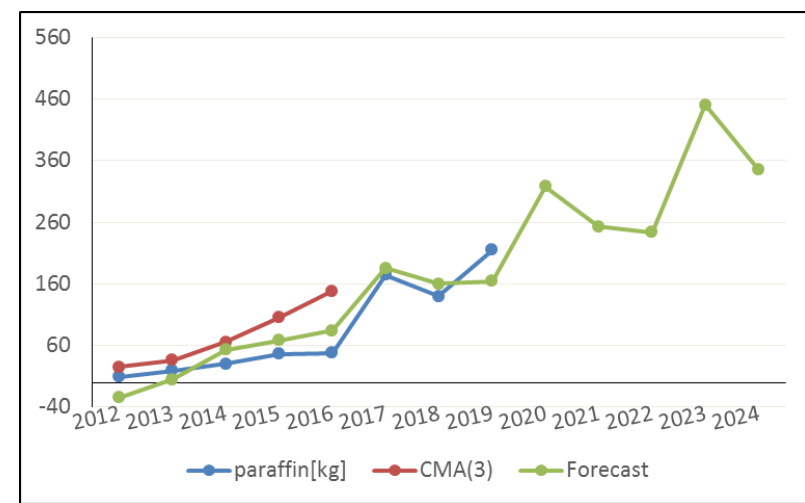

Figure 6. Forecast of paraffin chemical waste

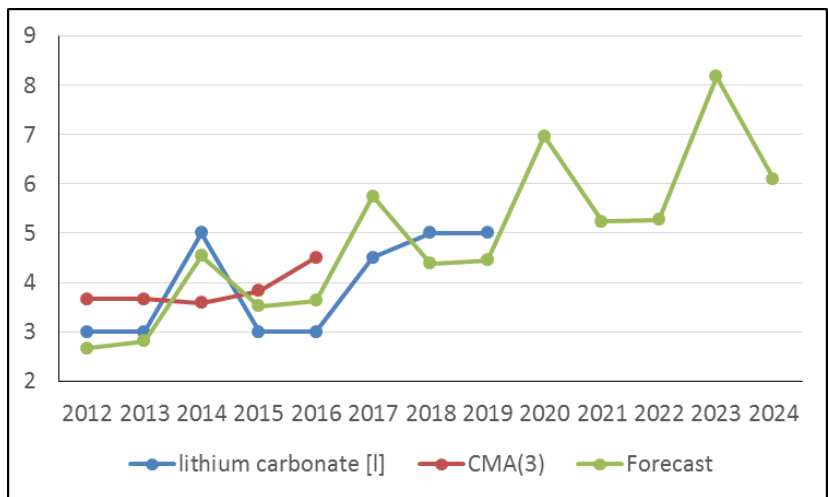

Figure 8. Forecast of lithium carbonate chemical waste

Similar interpretations can be made for all the consumption of substances presented in Figures 1-8.

Regarding the dilute acid mixtures and the organic solvent mixtures, due to the small number of recorded data, the trendline is not significant, the $\mathrm{R}^{2}$ parameter being far from the recommended values $\{1 ;-1\}$. Figures 9 and 10 reveal that the most important amounts of dilute acid mixtures and organic solvent mixtures were recorded in 2017, while in 2018 the amounts decreased, and remained approximately constant in 2019. 


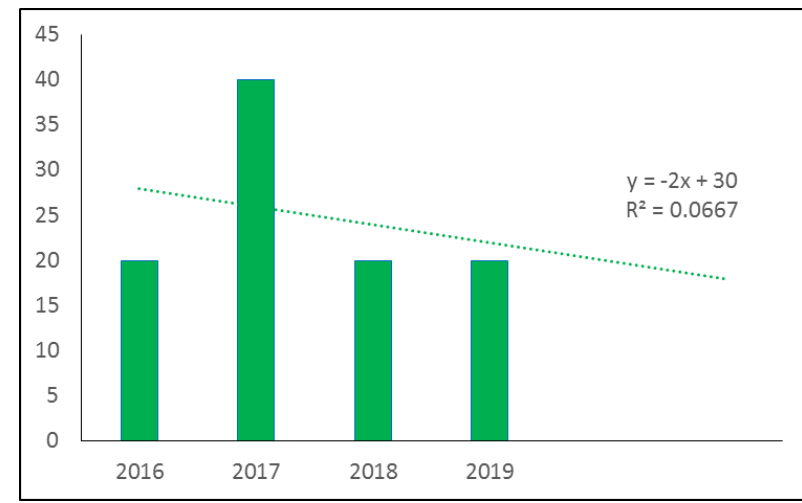

Figure 9.Trendline of dilute acid mixtures

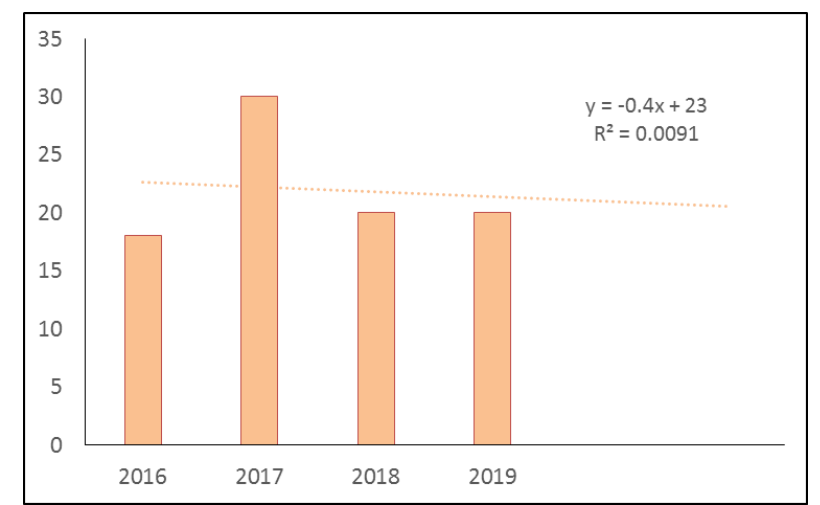

Figure 10.Trendline of organic solvent mixtures

\section{Conclusions}

The forecast of almost all chemical waste reveal the fact that the amount of hazardous chemical waste is growing steadily for the next 5 years. A decrease in the amount of chemical waste resulting from the activity of medicolegal laboratories is recorded for carboxylol. This requires a change in strategy regarding the management of hazardous chemical waste.

The most important strategic objectives for the next period should aim at the following:

-Localization and organization of facilities for temporary collection and storage of waste resulting from the activity of the forensic laboratory;

-Treatment and thermal decontamination at low temperatures (steam, hot air, etc.);

-Analyzing the result of decontamination and eliminating waste resulting from medical activities.

\section{References}

1.BRICHARD, K., 2002, January 5. Out of sight, out of mind...the medical waste problem. Lancet 359, 56. http://dx.doi.org/10.1016/S0140-6736(02)07256-2

2.MOHEE, R., 2005. Medical wastes characterization in healthcare institutions in Mauritius. Waste Manag. 575e581.http://dx.doi.org/10.1016/j.wasman.2004.10.003

3.PERJU-DUMBRAVA, D., CHIROBAN, O., FULGA, I., Aortoenteric fistula: a possible cause of sudden death. Case report, Romanian Journal of Legal Medicine,21(1), 2013,19-22.

4.FULGA, I., MUSAT, L.C., CRASSAS, R., CEAVDARI, N. Child sexual abuse: offender's modus operandi aspects in intra-agresional period, Romanian Journal of Legal Medicine,16(1), 2008, 31-36.

5.MORARU, M., CHITESCU, C.L., NECHITA, A., MACOVEI, L.A., FULGA, I., LC-Highresolution MS Analysis of the Designer Drugs Methylenedioxy-Pyrovalerone (MDPV) and Methylenedioxy-alphapyrolidinobutyrophenone (MDPBP) and Their Main Metabolites in Human Urine, Rev. Chim., 69(10), 2018, 2916-2920.

6.CHITESCU, C.L., RADU, A.D., ACIU, F., MORARU, M., FULGA, I., New psychoactive substances (NPSs) abuse in Romania: analytical strategies for drug screening in biological samples using high resolution mass spectrometry, Romanian Journal of Legal Medicine, 26(2), 2018, 173-182.

7.PERJU-DUMBRAVA, D., ANITAN, S., SISERMAN, C., FULGA, I., OPINCARU, I., Virtopsy an Alternative to Conventional Autopsy, Romanian Journal of Legal Medicine, 18(1),2010,75-78.

8.CRAESCU, M.; REBEGEA, L.; IVAN, I.; DUMITRU, M.; SERBAN, C.; FIRESCU, D.. Therapeutic challenges in a case of trachea neuroendocrine tumor, Acta Medica Mediterranea, Medica 3, 2019, 2283-9720

9.IOV TATIANA, COSTESCU MIHNEA, DIAC MADALINA, TABIAN DANIEL, DAVID SOFIA MIHAELA, KNIELING ANTON, DAMIAN SIMONA IRINA, Dangerous Chemical Agents: General and Odonto-Stomatological Aspects with Importance in Forensic Toxicology, Rev. Chim.,70(5), 2019, 1829-1834 
10.DAMIAN SIMONA IRINA, DIAC MADALINA, IOV TATIANA, HUNEA IULIANA, BULGARU ILIESCU DIANA, Particularities of Medical Education in the Field of Forensic Toxicology. Studying Dangerous Chemical Agents in Forensic Research, REVISTA ROMANEASCA PENTRU EDUCATIE MULTIDIMENSIONALA, 2019, 11(4): 337-344

11.PERJU DUMBRAVA, RADU CARMEN CORINA, DAVID SOFIA, IOV TATIANA, IOV CATALIN JAN, SANDU ION, ILIESCU DIANA BULGARU, The Importance of Alcohol Testing by Gas Chromatography vs the Cordebard Classical Method Modified in the Medico Legal Investigation, Rev. Chim., 69(9), 2018, 2407-2410

12.ALMUNEEF, M., MEMISH, Z.A., 2003. Effective Medical Waste Management: It Can Be Done. Association for Professionals in Infection Control and Epidemiology, Riyadh. http://dx.doi.org/ 10.1067/mic.2003.43

13.ANANTH, A.P., PRASHANTHINI, V., VISVANATHAN, C., 2010. Healthcare waste management in Asia. Waste Manag. 154e161. http://dx.doi.org/10.1016/j.wasman.2009.07.018.

Manuscript received: 14.04 .2020 